\title{
Porcelain veneer for a simple and esthetic treatment on anterior teeth with enamel hypoplasia: a case report
}

\author{
Juni Jekti Nugroho and Andi Hermianti Aco \\ Department of Conservative Dentistry, \\ Faculty of Dentistry, Hasanuddin University \\ Makassar, Indonesia
}

\begin{abstract}
Background: the esthetic factor should be considered for every patient who seeks a comprehensive dental treatment, especially for women. The anterior teeth deformities will diminish the levels of confidence and decrease self-esteem of the patients. The tooth development disturbances, such as enamel hypoplasia, may present an esthetic problem. Enamel hypoplasia is an alteration of organic matrix formation which characterized by the defect or porosity on the enamel surface. It can be restored with a variety of restorative treatment options including indirect porcelain veneers. Case: a 30 years old female patient was referred with chief complaint of anterior teeth discoloration. Clinical examination on the maxillary left central and lateral incisors revealed the defects on nearly half of the labial surface. Case management: the incisal lapping technique were chosen to prepared teeth \#21 and \#22 for indirectporcelain veneerfabrications. Conclusion: indirect porcelain veneers established an excellent esthetic result and restored the size, shape and color of anterior teeth with long term stability.
\end{abstract}

Keywords: enamel hypoplasia; esthetic; indirect porcelain veneer

Correspondence: Juni Jekti Nugroho. Department of Conservative Dentistry, Faculty of Dentistry, Hasanuddin University. J1. Perintis Kemerdekaan KM 10. Tamalanrea, Makassar Indonesia, 90245. E-mail: jektijuni@unhas.ac.id

\section{INTRODUCTION}

One of the problems in dentistry is the increasing enamel hypoplasia. Enamel hypoplasia is an enamel malformation that reduced the enamel quality that may relate to brittle teeth or even poor esthetic. In severe conditions, it is manifested clinically as tooth structure and anatomy alterations, which usually seen as a depression or groove on the enamel surface..$^{1,2,3}$ Enamel hypoplasia is one of the cause of reduced enamel quality. ${ }^{1,2,3}$ A recent study by Ayuandyka and Ghalib (2016), reported the prevalence of enamel hypoplasia of preschool children 4-6 years old in Makassar-Indonesia was $44.27 \%$, and mostly found on anterior teeth was $52.2 \%{ }^{4}$ Enamel hypoplasia can be improved with a variety of treatment options, such as porcelain or composite veneer, ${ }^{5,6,7}$ bleaching, ${ }^{8}$ full coverage crown, ${ }^{6}$ or micro-abrasion. ${ }^{9}$ There were 2 types of veneer based on the materials, i.e composite and porcelain. A restorative treatment which was done by coating all the labial surface with composite resin that are known by the term "direct veneers" becomes a treatment option that provides better esthetic results, but in cases of severe enamel hypoplasia, an indirect veneer with porcelain material was considered as the most appropriate treatment option. ${ }^{9,10}$
Based on the preparation form, veneer was classified as the partial- and full-veneer. The partial veneer is indicated to restore localized defects or areas with intrinsic discoloration, whilst full veneer is indicated to restore wider areas of defects or intrinsic discoloration areas. The veneer preparation is broadly divided into 3 designs, including incisal butt joint, window, and incisal lapping preparation. ${ }^{11,12}$

The treatment planning for a patient with enamel hypoplasia was affected by several factors, such as age, socioeconomic status, severity and type of the defects, and also the intraoral condition. The main principle considered in the fabrication of the tooth restoration is the cavity preparation, to cut the sound structures as minimal as possible. ${ }^{11-13}$ This case report described about indirect veneer restoration to manage enamel hypoplasia on teeth $\# 21$ and \#22.

\section{CASE}

A 30 years old female came to the Hasanuddin University Dental Hospital, Makassar with brownish discoloration and depressions on the anterior teeth from 7 years ago. She needs to improve the dental esthetics. The medical history 
was non-contributory and good oral hygiene. Clinical examination on the maxillary left central and lateral incisors revealed the defects on nearly half of the labial surface (Figure 1A). The diagnostic determined for the teeth was pulpitis reversible.

\section{CASE MANAGEMENT}

On the first visit, examination of teeth, soft tissue, and oral hygiene condition of the patients were performed. The shade guide A3 (VITAPAN classical-VITA Zahnfabrik, Germany) was used to select the tooth color before preparation procedures was began. The gingival sulcus was managed using the retraction cord number 00 (SURE-Cord, Sure-endo Sure Dent Co., Korea). The veneer preparation was conducted with deep cutting bur, followed by tapered diamond bur (Laminate Veneer System-Set 4151, KOMET USA). The chamfer cervical preparation was made on the labial surface parallel to the gingival margin. The incisal edge was cut approximately $1 \mathrm{~mm}$. The proximal preparation was extended onto the interproximal contact (Figure 1B and 1C). The double impression technique was done (EXAFLEX-Vinyl Polysiloxane, GC, Tokyo, Japan) and the temporary veneer (Revotec LC- GC, Tokyo, Japan) was inserted at this appointment.

At the second visit, the try-in procedures were done after the temporary veneer was removed. And the occlusion was inspected. The veneer surfaces were cleaned, air-dried, and the silane coupling agent (Silane-Ultradent Products, Inc. South Jordan, Utah, USA) was applied. A celluloid strip was placed in the interdental area of the maxillary left central and lateral incisors. The luting cement (BREEZE self-adhesive resin cement, Pentron Clinical, Europe) was applied on the veneer, and inserted onto the teeth, pre-cured was done for 2 seconds. The celluloid strip (DentAmerica Mylar stripDentamerica, USA) was removed and the cement excess was removed using an explorer, the veneer was cured for another 20 seconds on all aspects (Figure 1D).
After the follow up visit 6 months later, veneer on teeth \#21 and \#22 were examined. There were no subjective complaints from the patient. On clinical examination, a normal gingival tissue without veneer discoloration was noted (Figure 1E).

\section{DISCUSSION}

Enamel hypoplasia was defined as a reduction of enamel thickness due to disturbances in the matrix apposition stage during the enamel development. This alteration may affected genetically (e.g. amelogenesis imperfecta) or due to environmental factor (pre- and post-childbirth). Clinically, enamel hypoplasia manifested as white spots, depressions, grooves, or as enamel thinning and tooth discoloration, from slightly yellow to brownish. This condition may increase the susceptibility to occur caries, tooth wear, sensitivity and poor esthetics clinically. $5,6,11,12,14$

In this case report, we were describing about the loss of tooth structures and a severe defect that affecting the dentine, in which porcelain veneer restoration was considered as the most appropriate treatment option. The sound tissue preparation in the indirect veneer restoration was minimal, approximately $0.5-0.7 \mathrm{~mm}$. We performed a full veneer preparation in tooth \#21 and \#22 not only to manage the large defects on the tooth surface and reduce the tooth sensitivity and strengthen the teeth, but also to improved its esthetics. An alternative in the full veneer preparation is incisal lapping preparation technique that we used in this case, which was based on the localized defect in the middle of the labial surface of teeth \#21 and \#22 which almost reach the incisal edge, therefore the preparation was extended to the incisal edge. ${ }^{11,14,15}$

Indirect porcelain veneer was indicated for the discolored and hypocalcified teeth, diastema, tooth-shaped correction, and tooth malposition which cannot be managed orthodontically. There are contraindications for porcelain indirect veneer, such as bruxism patients, inadequate enamel

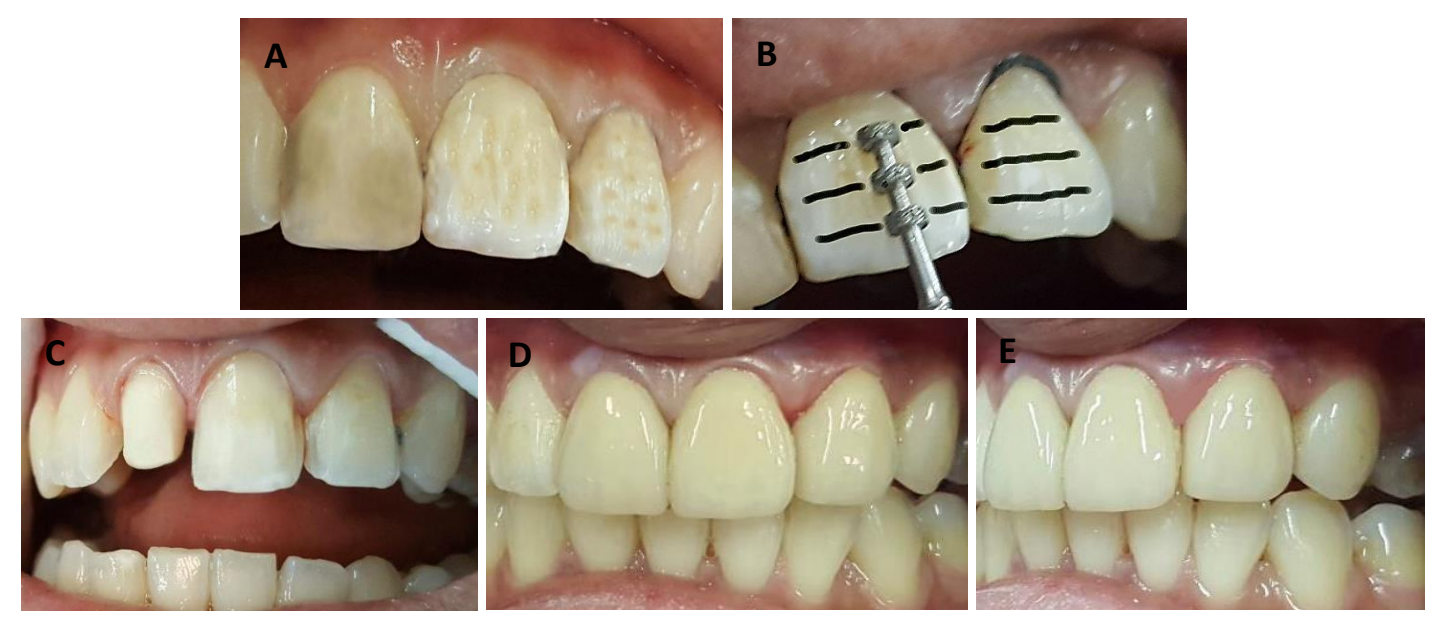

Figure 1. (a) Pre-treatment clinical view. (b) The depth cutting bur preparation technique. (c) Post-preparation view of $\# 21$ and $\# 22$. (d) Post-treatment view. (e) Follow up after 6 months. 
thickness for retention, severe tooth fracture, large diastema, shortened-crown tooth, teeth with large restoration, severe tooth discoloration. ${ }^{14}$

Indirect porcelain veneers have more advantages than composite resin veneer because it has better esthetic, color stability, durable to withstand high abrasions, biocompatible, and non-porous, therefore plaque accumulation and its adverse effects on the gingival health can be minimized. ${ }^{11}$, 14, 15 Touti (1999), stated that the advantages of porcelain veneers are resistant to plaque attachments, the preparation was limited to the enamel to protect the tooth structure underneath. Maintaining a sound tooth structures as much as possible are an essential part that should be considered in the dental restoration. ${ }^{11,15}$

\section{CONCLUSION}

In this case, enamel hypoplasia was restored with indirect porcelain veneer which provided an esthetic result. Nevertheless, proper case selections, sufficient equipment, and adequate operator skills are needed to achieve the optimum treatment results.

\section{REFERENCES}

1. Cheranjeevi J, Prashant C, Karthik V, Krisnha T, Shalin S, Anila B. Linear Enamel Hypoplasia: case report J of Adv. Oral. Res. 2013; 4(3): 12-15.

2. Slayton RL, Warren JJ, Kanellis MJ, Levy SM, Islam M. Prevalence of enamel hypoplasia and isolated opacities in the primary dentition. Am. Aca of Pediatr. Dent. 2001; 23(1):
32-36.

3. Fonseca RB, Sobrinho LC, Neto AJF, da Mota AS, Soares CJ. Enamel hypoplasia or amelogenesis imperfecta - a restorative approach. Braz. J Oral Sci. 2006; 5(16): 941-943.

4. Ayuandyka U, Ghalib N. Prevalence of tooth discoloration in preschool children in Makassar. Makassar Dent J. 2016; 5 (Supl 1): 9.

5. Peumans M, Meerbeek BV, Lambrechts P, Vanherle G. Porcelain veneers; a review of the literature. J of Dent. 2000; 28:163-177.

6. Mathew CA, Sabeena M, Karthik KS. A review on ceramic laminate veneers. JIACDS. 2010; 1(4): 33-36.

7. Bhoyar AG. Esthetic closure of diastema by porcelain laminate veneers; a case report. People's J of Sci. Res. 2011; 4(1): 45-50

8. Joiner A. The bleaching of teeth: A review of the literature. J of Dent. 2006; 34: 412-419.

9. Shenoi P, Kandhari A, Gunwal M. Esthetic enhancement of discolored teeth by macroabrasion microabrasion and its psychological impact on patients - A case series, Indian. J of Multidiscip Dent. 2011; 2(1): 388-392.

10. Khozeimeh F, Khademi H, Ghalayani P. The prevalence of etiologic factors for tooth discoloration in female students in Isfahan High Schools. Dent. Res. J. 2008; 5(1): 13-16.

11. Krenz M. Enamel hypoplasia in contemporary population from Poznan (Poland): Methodics and preliminary results. Variability and Evolution, 1994; 4:73-88.

12. Heymann HO. Additional Conservative Esthetic Procedures. In: Heymann HO, Swift Jr EJ, Ritter AV, editors. Sturdevant's Art and Science of Operative Dentistry. $6^{\text {th }}$ ed. St. Louis: Mosby; 2013. 296-338.

13. Martos J, Gewehr A, Paim E. Aesthetic approach for anterior teeth with enamel hypoplasia. Contemp. Clin. Dent. 2012; 3(Suppl 1): S82-S85 (DOI:10.4103/0976-237X.95112).

14. Sowmya S, Sunitha S, Dhakshaini MR, Raghavendraswamy KN. Esthetics with veneers: A review. IJDHC. 2015; 1: 1-5.

15. Watts A, Addy M. Tooth discoloration and staining: a review of the literature. Bri Dent J. 2001; 190(6): 309-316. 